\title{
Closing capacity of segmental radius defects in rabbits
}

\author{
Esther W.H. Bodde, ${ }^{1}$ Paul H.M. Spauwen, ${ }^{2}$ Antonios G. Mikos, ${ }^{3}$ John A. Jansen ${ }^{1}$ \\ ${ }^{1}$ Department of Periodontology and Biomaterials, Radboud University Nijmegen Medical Center, \\ Nijmegen, P.O. Box 9101, 6500 HB, the Netherlands \\ ${ }^{2}$ Department of Plastic and Reconstructive Surgery, Radboud University Nijmegen Medical Center, Nijmegen, \\ P.O. Box 9101, 6500 HB, the Netherlands \\ ${ }^{3}$ Department of Bioengineering, Rice University, Houston, Texas 77251-1892
}

Received 7 December 2006; revised 8 May 2007; accepted 28 May 2007

Published online 9 August 2007 in Wiley InterScience (www.interscience.wiley.com). DOI: 10.1002/jbm.a.31549

\begin{abstract}
In the research of synthetic bone graft substitutes, the relevance for bone regeneration can be confirmed in a critical-sized model. In this study the rabbit radial defect was investigated as an ingenious model of critical size, due to its defect immobilizing intact ulna. In addition, the influence of poly(DL-lactic-co-glycolic acid) (PLGA) on bone regeneration was determined. Sixteen, 4month-old rabbits received bilateral segmental radial defects of 15 or $20 \mathrm{~mm}$. The osteotomy ends were marked with small titanium pins. Half of the group received injected PLGA microparticle/carboxymethylcellulose implants. Implantation time was 12 weeks. Evaluation consisted of radiographs after surgery and sacrifice, microcomputed tomography and histology. The radiographs revealed that the created defects were significantly smaller
\end{abstract}

after sacrifice. Further a number of radii showed fibrocartilaginous interposition. Both findings indicated instability of the created defect. All evaluation techniques revealed that 15 and $20 \mathrm{~mm}$ were not of critical size, as most defects were more or less regenerated. PLGA microparticles did not influence bone regeneration significantly. In conclusion, 15- and 20-mm radius defects in 4-month-old rabbits were not a suitable model for bone regeneration as these defects were neither critical size nor stable. PLGA-microparticle degradation did not influence bone regeneration. (C) 2007 Wiley Periodicals, Inc. J Biomed Mater Res 85A: 206-217, 2008

Key words: radius defect; critical-size; rabbit model; PLGA; microparticles

\section{INTRODUCTION}

Long bone segmental defects remain a difficult clinical problem to manage. ${ }^{1}$ Synthetic bone graft substitutes are expected to be of major importance in the treatment of these large bone defects. However, the osteoregenerative potential of these bone substitutes still needs to be improved to obtain materials equivalent to autologous bone.

In the evaluation of artificial bone regenerative materials, the so-called "critical-size defect" (CSD) is an essential model. A CSD is defined as the smallest size of a defect, that does not heal spontaneously when left untreated for a certain time period ${ }^{2}$ or that shows less than $10 \%$ bone regeneration during the lifespan of an animal. ${ }^{3}$ The effectiveness of bone graft substitutes in bone regeneration can be proven when the materials overcome the nonhealing of criti-

Correspondence to: J. A. Jansen; e-mail: j.jansen@dent. umcn.nl

(C) 2007 Wiley Periodicals, Inc. cal-sized bone defects. Several CSD models in different animals have already been described, each with their own specific application. For instance, calvarial defects in rats and rabbits provide good first phase nonload bearing bone models with relative biological inertness due to poor blood supply and limited bone marrow, resembling atrophic mandibular bone in humans. ${ }^{3}$ A good site for studying the regeneration of segmental long bone defects is the mid-diaphyseal radius. It is claimed that this model does not need internal fixation or external splinting in small animals as the adjacent intact ulna provides stability to the created radial defect. ${ }^{4-9}$ Consequently, operation time and costs are minimized and the risk of infection is reduced. For first phase research, before large animal implantation, rabbits are interesting as experimental animals, as their bones are large enough to evaluate material handling properties in comparison to rats for instance. However, a review of the literature shows that the exact critical size of radial defects in rabbits is not clear. ${ }^{4,5,7,10-13}$ Disregarding study dissimilarities, it varies between 10 and $20 \mathrm{~mm}$ in general. Earlier studies in our laboratory investigated 
polymeric scaffolds for degradation and bone formation in 15-mm segmental radial rabbit defects. ${ }^{6,14}$ Although the model was found to be suitable to test these scaffold materials, empty defects did not confirm a critical size of $15 \mathrm{~mm}$ for a time period of 12 weeks, because some of the defects had closed. Currently, analysis techniques mainly consist of radiographs and histology. Because of the two-dimensional nature of these techniques, localization and quantification of newly formed bone in and around a defect site can be difficult. A more complete analysis can be done using three-dimensional images provided by microcomputed tomography $(\mu \mathrm{CT})^{15-17}$ for example. In the present study, the critical size for mid-diaphyseal radial defects in rabbits was assessed by radiographs, $\mu \mathrm{CT}$ images, and histology.

Besides determining the critical size of a radial defect, the rationale for the current study was to evaluate poly (DL-lactic-co-glycolic acid) (PLGA) for its influence on bone regeneration. Our laboratory focuses on calcium phosphate cement as an artificial bone regenerative material. To obtain an injectable and degradable biomaterial, microparticles of PLGA are added. The microparticles initially stabilize the paste but will also degrade over time, leaving macropores behind. Subsequently, these macropores can improve the degradation rate of the cement, similar to that shown by del Real et al. ${ }^{18}$ for a non-in vivo injectable $\mathrm{CO}_{2}$-induced macroporous cement placed in trabecular bone defects in goats, as a result of increased specific surface area and enhanced tissue ingrowth into the material porosity. Besides acting as a porogen, PLGA can also be used as a delivery vehicle for growth factors ${ }^{19-21}$ in order to further enhance the bone regenerative effect of the calcium phosphate cement. PLGA is a biodegradable polymer, used clinically in suture material and is considered to be biocompatible. ${ }^{22,23}$ The polymer degrades by random hydrolysis into nontoxic lactic and glycolic acids which are eliminated from the body through respiration and excretion in the urine. ${ }^{21,24,25}$ Although PLGA is claimed to be biocompatible, the degradation of PLGA is associated with the release of acidic degradation products. ${ }^{24,26}$ Therefore, the current study focused on PLGA as a possible parameter influencing bone regeneration. Carboxymethylcellulose $(\mathrm{CMC})$ was used as a carrier biomaterial for the PLGA microparticles. The polysaccharidebased hydrogel is biocompatible $e^{21,27}$ and is known to provide good plasticity as well as good space-keeping properties. ${ }^{28,29}$ This carrier material has been reported to not interfere with osteogenesis. ${ }^{29-31}$

In view of what has been mentioned earlier, the rationale for the current study was to investigate the mid-diaphyseal radial defect in rabbits as a criticalsize model. In addition, the regenerative capacity of a composite of PLGA microparticles in CMC was investigated in this segmental bone defect model. We hypothesized that PLGA would not influence bone regeneration.

\section{MATERIALS AND METHODS}

\section{Preparation of PLGA microparticles}

PLGA (Purasorb ${ }^{\mathbb{R}}$, Purac, Gorinchem, The Netherlands) with a lactic to glycolic acid copolymer ratio of 50:50 and a molecular weight of $48.0 \pm 1.6 \mathrm{~kg} / \mathrm{mol}$ was used to prepare microparticles with a double-emulsion-solvent-extraction technique ([water-in-oil]-in-water). ${ }^{19,26,32-34}$ This consisted of the injection of $500 \mu \mathrm{L}$ distilled water into a tube containing a solution of $1.0 \mathrm{~g}$ PLGA in $4 \mathrm{~mL}$ dichloromethane. This mixture was emulsified for $60 \mathrm{~s}$ on a vortexer. Then $6 \mathrm{~mL} \mathrm{0.3 \%} \mathrm{aqueous} \mathrm{poly(vinyl} \mathrm{alcohol)} \mathrm{(PVA,} \mathrm{Acros}$ Organics, Geel, Belgium) solution was added and emulsified for another $60 \mathrm{~s}$ to produce the second emulsion. This mixture was added to $394 \mathrm{~mL} 0.3 \%$ PVA solution and $400 \mathrm{~mL}$ of $2 \%$ isopropylic alcohol solution and was stirred for $1 \mathrm{~h}$. The evaporation of the solvent resulted in precipitation of the dissolved polymer and the subsequent formation of microparticles. The microparticles were allowed to settle for $15 \mathrm{~min}$ and the solution was decanted. Then, the microparticles were collected through centrifugation at $1500 \mathrm{rpm}$ for $5 \mathrm{~min}$, lyophilized to dryness and stored under argon at $-20^{\circ} \mathrm{C}$ until use. Size distribution of the PLGA microparticles was determined by image analysis (Leica Qwin ${ }^{\mathbb{R}}$, Leica Microsystems). The PLGA microparticles were sterilized by glow discharge (Plasma cleaner/ sterilizer, Harrick Scientific, Ossining, New York, USA).

\section{Preparation of injectable PLGA implant}

The polysaccharide-based hydrogel CMC (cekol 50.000) (Noviant BV, Nijmegen, the Netherlands) was used as a carrier material for the PLGA microparticles. CMC powder was sterilized by glow discharge. The powder $(4 \%)$ was mixed with sterile distilled water according to the manufacturer's instructions in order to form a gel with a puttylike appearance. Prior to surgery the PLGA microparticles were added to the CMC solution in a $20 \mathrm{wt} \%$ ratio, as pilot studies performed in our laboratory (unpublished data) had shown that this ratio provided an injectable material with good consistency and homogeneous divided microparticles. The PLGA/CMC composite was injected into the mid-diaphyseal radial defects using a $1 \mathrm{~mL}$ syringe (Becton \& Dickinson, USA) with a 4.7-mm diameter and the tip cut off.

\section{Surgical procedure}

Sixteen healthy 4-month-old (about 16 weeks) female New Zealand White rabbits, with a weight of $2.7-3.4 \mathrm{~kg}$ were included in this study. National guidelines for the care and use of laboratory animals were observed. All animals were screened for good physical condition. 
The operation was performed under general inhalation anesthesia. The anesthesia was induced by an intravenous injection of Hypnorm ${ }^{\mathbb{R}}(0.315 \mathrm{mg} / \mathrm{mL}$ fentanyl citrate and $10 \mathrm{mg} / \mathrm{mL}$ fluanisone; Janssen Pharmaceutica, Beerse, Belgium) and atropine and maintained by a mixture of nitrous oxide, isoflurane, and oxygen through a constant volume ventilator. The rabbits were connected to a heart monitor. To reduce perioperative infection risk, antibiotic prophylaxis was given (Baytril ${ }^{\mathbb{R}}$ 2.5\% enrofloxacin, 5-10 $\mathrm{mg} / \mathrm{kg}$; Bayer Healthcare, Mijdrecht, the Netherlands).

The rabbits were immobilized on their abdomen. Both forelimbs were shaved, washed, and disinfected with povidone-iodine. A 4.5-cm longitudinal incision was made along the radius. After dissecting the muscles and exposure of the radius, a segmental defect of 15 or $20 \mathrm{~mm}$ was created in the middle of the radius using a dental burr (Elcomed 100, W\&H Dentalwerk Burmoos GmbH, Austria) with a diamond blade (Horico, Berlin, Germany) at a rotating speed of $800 \mathrm{rpm}$ and under continuous saline cooling. A titanium rod of 15 or $20 \mathrm{~mm}$ was used to obtain defects with standardized size. The periosteum was resected with the bone segment and the intervening membrana interossea was removed as well. The osteotomy ends were marked with titanium bone markers (Stabilok ${ }^{\circledR}$, Fairfax Dental, Ireland) at a distance of $7 \mathrm{~mm}$ from the bone edge. Four experimental groups were specified (15-mm open defect, 20-mm open defect, 15-mm defect with PLGA implant, and 20-mm defect with PLGA implant) and the animals were randomly assigned to one of these groups (Table I). The implant consisting of the PLGA/CMC composite was injected into the defects using a 1-mL syringe (Becton \& Dickinson) with a $4.7-\mathrm{mm}$ diameter and the tip cut off (Fig. 1). The implant retained its shape in accordance with the defect size due to its putty-like appearance. No additional fixation was used for the implants. Finally, the soft tissues were closed in separate layers using resorbable Vicryl ${ }^{\mathbb{R}} 4.0$ (Johnson and Johnson, St. StevensWoluwe, Belgium) sutures. The surgical procedure was identical on both sides. An X-ray of both forelimbs was

TABLE I

Implantation Scheme Indicating for Each Rabbit and Limb Side the Defect Size and Type of Group Consisting of (-) Open Defect or (+) PLGA Implant

\begin{tabular}{ccc}
\hline Rabbit No. & Right Limb & Left Limb \\
\hline 1 & $20 \mathrm{~mm}-$ & $20 \mathrm{~mm}+$ \\
2 & $20 \mathrm{~mm}+$ & $20 \mathrm{~mm}-$ \\
3 & $20 \mathrm{~mm}-$ & $20 \mathrm{~mm}+$ \\
4 & $20 \mathrm{~mm}+$ & $20 \mathrm{~mm}-$ \\
5 & $15 \mathrm{~mm}-$ & $15 \mathrm{~mm}+$ \\
6 & $15 \mathrm{~mm}+$ & $15 \mathrm{~mm}-$ \\
7 & $15 \mathrm{~mm}-$ & $15 \mathrm{~mm}+$ \\
8 & $15 \mathrm{~mm}+$ & $15 \mathrm{~mm} \mathrm{-}$ \\
9 & $15 \mathrm{~mm}-$ & $15 \mathrm{~mm}+$ \\
10 & $15 \mathrm{~mm}+$ & $15 \mathrm{~mm}-$ \\
11 & $15 \mathrm{~mm}-$ & $15 \mathrm{~mm}+$ \\
12 & $15 \mathrm{~mm}+$ & $15 \mathrm{~mm}-$ \\
13 & $20 \mathrm{~mm}-$ & $20 \mathrm{~mm}+$ \\
14 & $20 \mathrm{~mm}+$ & $20 \mathrm{~mm}-$ \\
15 & $20 \mathrm{~mm}-$ & $20 \mathrm{~mm}+$ \\
16 & $20 \mathrm{~mm}+$ & $20 \mathrm{~mm}-$ \\
\hline
\end{tabular}

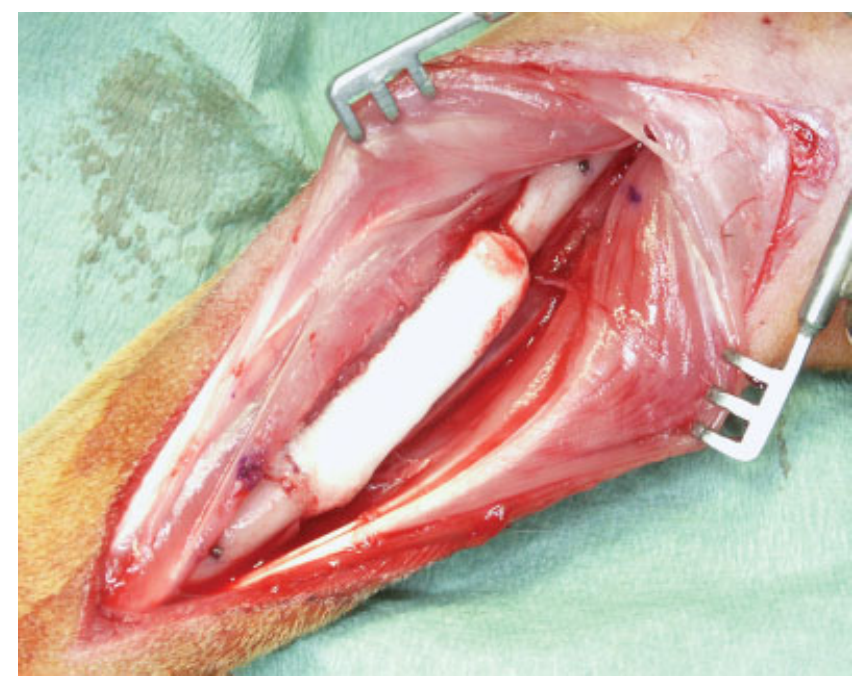

Figure 1. A segmental mid-diaphyseal radial defect in the forelimb of a rabbit with a PLGA microparticle/CMC composite injected into the defect. [Color figure can be viewed in the online issue, which is available at www. interscience.wiley.com.]

made immediately after surgery (Mobilett X-ray machine, Siemens, Munich, Germany) and the distance between the Ti-markers was measured.

To minimize postoperative discomfort, Finadyne ${ }^{\circledR}$ (Schering-Plough, Segre, France) $1 \mathrm{mg} / \mathrm{kg}$ was administered intramuscularly preoperatively and was continued for 2 days after surgery. Some contradiction about the use of this nonsteroidal antiinflammatory drug (NSAID) in bone surgery exists, as bone repair could possibly be impaired. ${ }^{35}$ However, as in humans these drugs are a standardized postoperative regimen for pain relief, ${ }^{36}$ we believe that administration in our experimental animals is justified.

The animals were housed individually in cages and were observed for signs of pain, infection, and proper activity. Twelve weeks after surgery the rabbits were sacrificed by an intravenous injection of Nembutal (pentobarbital) (CEVA Sante Animale BV, Libourne, France).

\section{Radiographs}

After sacrificing the animals, the radii were retrieved immediately and excess soft tissue was removed. Radiographs were made (Mobilett X-ray machine, Siemens, $\mathrm{Mu}$ nich, Germany) and evaluated using a modified system to score defect bridging and bone formation ${ }^{16}$ [Fig. 2(A,B)]. The distance between the Ti-markers was also measured.

\section{Microcomputed tomography}

Subsequently, any excess of bone was cut off with a diamond saw and the specimens were fixed in phosphate-buffered formaldehyde solution $(\mathrm{pH}=7.4)$ and dehydrated in ethanol $70 \%$. Then, $\mu \mathrm{CT}$ was performed to analyze defect bridging and bone volume. The specimens were wrapped 


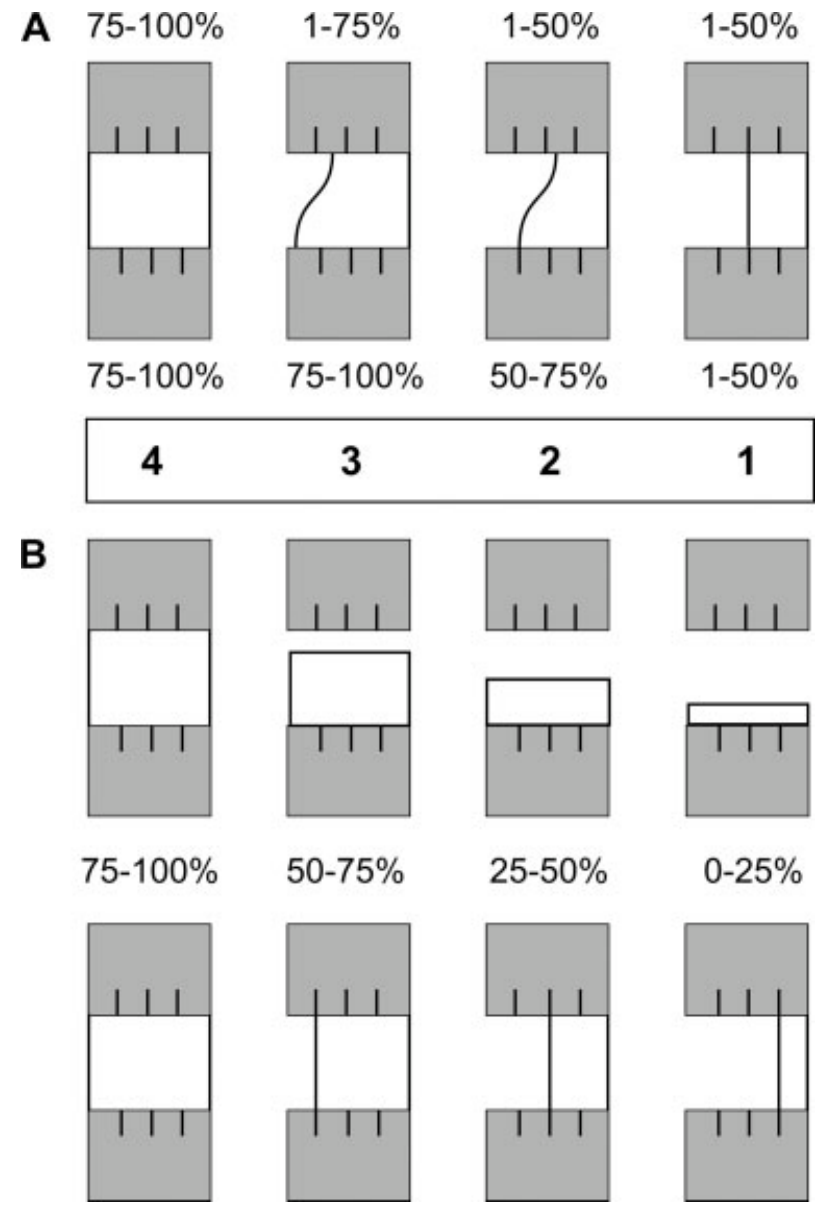

Figure 2. Modified scoring system for the quantitative evaluation of radiographs and $\mu \mathrm{CT}$ images. (A) Degree of bridging. Values refer to the percentage of contact surface of bridged bone at each side of the defect. (B) Bone formation in the defect. Values refer to the percentage of the defect area that is filled with bone. A score of zero was used when no bone bridging or bone formation was found.

in Parafilm $\mathrm{M}^{\mathrm{R}}$ (Pechiney Plastic Packaging, Chicago, USA) to prevent drying during scanning. Thereafter, all samples were scanned at a voltage of $101 \mathrm{kV}$ and intensity of $96 \mu \mathrm{A}$ with a resolution of $18.69 \mu \mathrm{m}$ using an aluminum filter $(1 \mathrm{~mm})$ (Skyscan-1072 X-ray microtomograph, TomoNT version 3N.5, Skyscan ${ }^{\circledR}$, Belgium). Cone-Beam reconstruction (version 2.15, Skyscan ${ }^{\mathbb{R}}$ ) was performed. All scanning and reconstruction parameters applied were identical for all specimens.

Three-dimensional images were created using 3D-creator (version $2.2 \mathrm{~h}$, Skyscan ${ }^{\mathbb{R}}$ ). These images were scored for defect bridging with the same modified scoring system as used for the radiographs ${ }^{16}$ [Fig. 2(A)]. The data were then further analyzed by CT Analyzer (version 1.4, Skyscan ${ }^{\circledR}$ ). The region of interest was specified as a area of $16.87 \mathrm{~mm}^{2}$ covering the ulna and radial defect over a length of $1 \mathrm{~mm}$ proximal to $1 \mathrm{~mm}$ distal of the osteotomy ends (Fig. 3). In this area bone volume $\left(\mathrm{mm}^{3}\right)$ was calculated for the ulna and regenerated radius, because it was impossible to distinguish between ulnar and regenerated radial bone. To quantify radial bone formation over time, radial defects

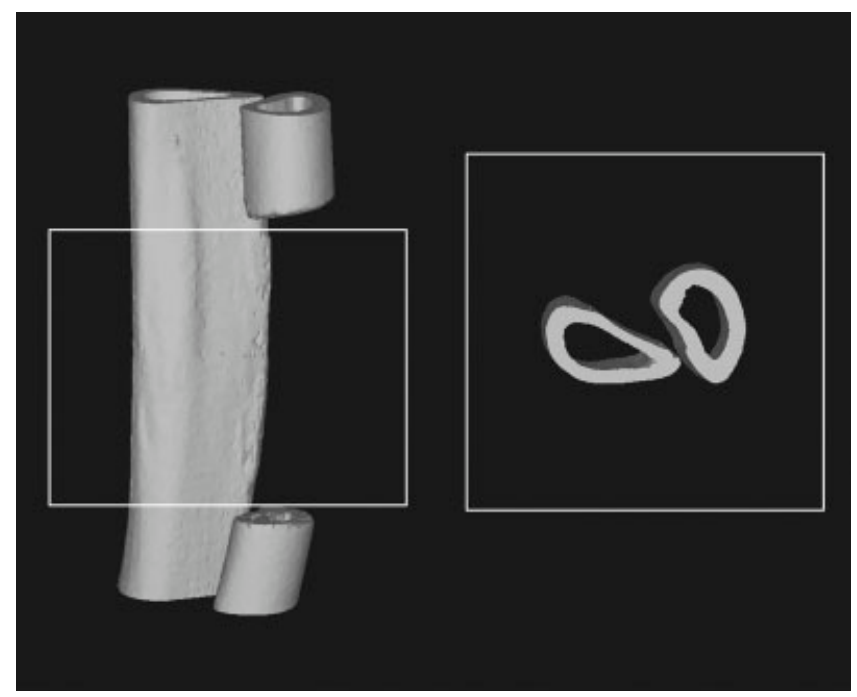

Figure 3. The region of interest as specified with CT Analyzer shown in a reference forelimb with a $15-\mathrm{mm}$ radial defect. A area of $16.87 \mathrm{~mm}^{2}$ covered the radial defect and ulna over a length of $1 \mathrm{~mm}$ proximal to $1 \mathrm{~mm}$ distal from the osteotomy sites.

were created in reference forelimbs $(n=4)$ of rabbits with identical weight and age (7 months old) as the experimental group, to determine the amount of ulnar bone. This average amount of ulnar bone in the reference rabbits was subtracted from the total (radial and ulnar) amount of bone after 12 weeks implantation to determine the amount of newly formed radial bone.

\section{Histological procedures}

After $\mu \mathrm{CT}$ was performed, the specimens were dehydrated in increasing ethanol concentrations (70-100\%) and embedded (nondecalcified) in methylmethacrylate. After polymerization, the specimens were hemisectioned through the center of the defect creating two halves. Thin sections $(10 \mu \mathrm{m})$ were prepared in a transverse direction of one half and a longitudinal direction of the other part using

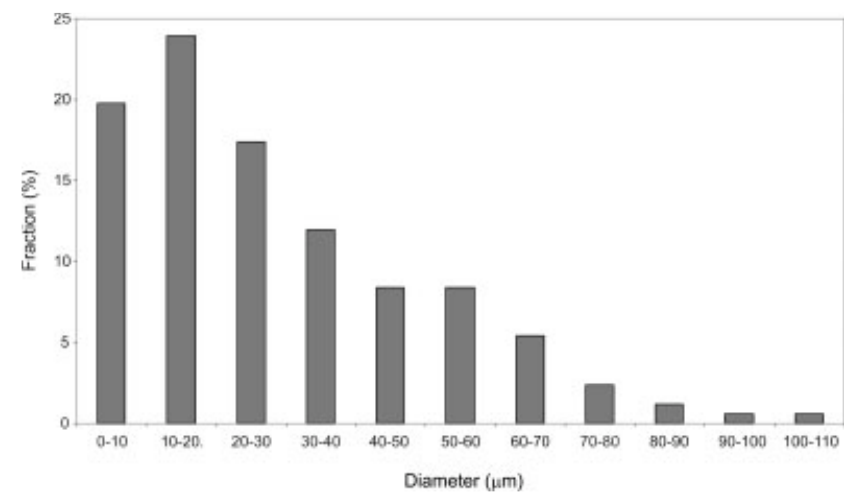

Figure 4. Size distribution of the PLGA microparticles prepared by a double-emulsion-solvent-extraction technique (group size $=166$ ). 


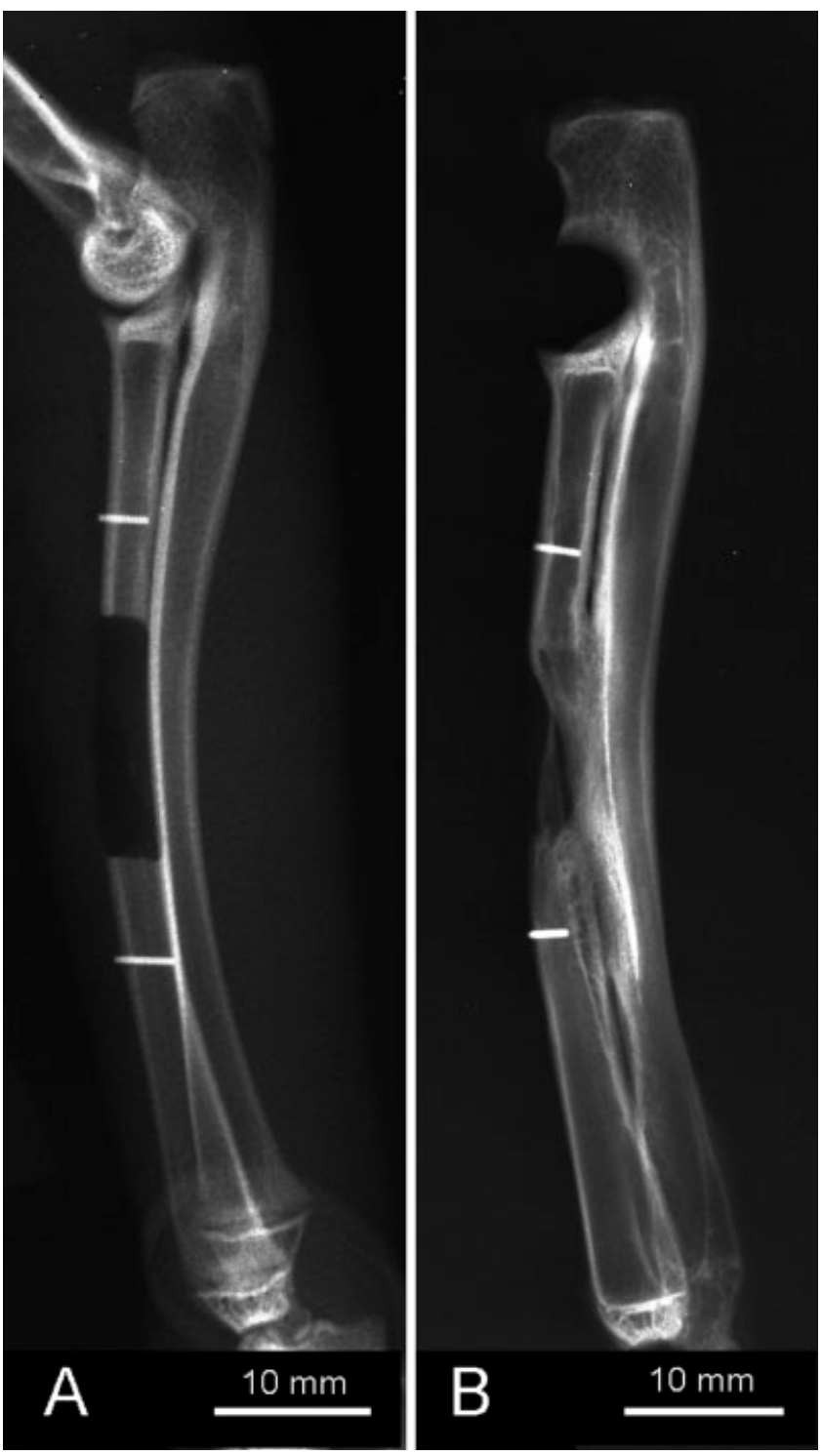

Figure 5. Representative X-rays of a $15-\mathrm{mm}$ defect after surgery (A) and sacrifice (B). The distance between the Timarkers was significantly reduced after sacrifice.

a microtome with a diamond blade (Leica Microsystems SP 1600, Nussloch, Germany). The sections were stained with methylene blue and basic fuchsin. The histological evaluation consisted of a morphological description of at least three sections of each implant using a light microscope (Leica Microsystems AG, Wetzlar, Germany).

\section{Statistical Analysis}

Statistical analyses were performed with GraphPad ${ }^{\mathbb{R}}$ Instat 3.05 software (GraphPad Software, San Diego, CA, USA) and SPSS (version 12.0.1, Chicago, USA). For comparison of the distance between the Ti-markers after surgery and sacrifice an unpaired $t$-test was used. The scoring of defect bridging and bone formation of the radiographs as well as defect bridging of the $\mu \mathrm{CT}$ images was analyzed with chi-square tests. $\mu \mathrm{CT}$ bone volume was evaluated with an unpaired $t$-test with Welch correction. Differences were considered significant at $p$-values less than 0.05 .

\section{RESULTS}

\section{Characterization of PLGA microparticles}

Figure 4 shows the size distribution of the PLGA microparticles prepared by a double-emulsion-solvent-extraction technique. The average size of the microparticles was $29 \pm 22 \mu \mathrm{m}$, as determined by image analysis (Leica Qwin ${ }^{\circledR}$, Leica Microsystems).

\section{Macroscopical evaluation}

All rabbits recovered from the surgical procedure well and in general no complications were encountered. One rabbit developed an infection unilaterally; this specimen was excluded from further analysis (20-mm defect with PLGA implant).

\section{Radiographs}

The X-rays made immediately after surgery confirmed that the created defects were indeed 15 (15.3 $\pm 0.6)$ and $20 \mathrm{~mm}(20.7 \pm 0.6)$ in size. The epiphyseal plates at this time point were not completely closed.

TABLE II

Results of the Radiographic Scoring for the Degree of Defect Bridging and the Amount of Bone Formation in 15 and 20-mm Defects With and Without PLGA Implants

\begin{tabular}{lrr}
\hline & Defect Bridging & Bone Formation \\
\hline 15 mm & & $2.6 \pm 1.3(4,1,1,2,2,3,4,4)$ \\
No implant & $2.4 \pm 1.6(4,0,1,1,2,3,4,4)$ & $2.4 \pm 1.2(2,4,2,2,1,3,4,1)$ \\
Implant & $2 \pm 1.4(1,4,1,1,1,3,4,1)$ & \\
20 mm & & $3 \pm 1.2(4,4,3,2,4,4,1,2)$ \\
No implant & $2.8 \pm 1.4(4,3,3,2,4,4,0,2)$ & $2.4 \pm 0.8(1,3,3,2,3,2,3)$ \\
Implant & $2 \pm 0.8(1,2,2,2,3,1,3)$ \\
\hline
\end{tabular}

Data represent the mean and standard deviations followed by the score per specimen. No significant differences among the groups were found. 
TABLE III

Results of the $\mu \mathrm{CT}$ Scoring for the Degree of Defect Bridging in 15 and 20-mm Defects With and Without PLGA Implants

\begin{tabular}{cc}
\hline & Defect Bridging \\
\hline $15 \mathrm{~mm}$ & \\
No implant & $1.9 \pm 1.6(4,0,0,1,2,3,1,4)$ \\
Implant & $2.6 \pm 1.7(1,4,4,3,0,4,4,1)$ \\
$20 \mathrm{~mm}$ & \\
No implant & $2.8 \pm 1.6(4,3,2,1,4,4,0,4)$ \\
Implant & $2.1 \pm 1.2(1,2,1,1,3,3,4)$ \\
\hline
\end{tabular}

Data represent the score per specimen followed by mean and standard deviations. No significant differences among the groups were found.

After retrieval of the specimens, the distance between the Ti-markers, placed $7 \mathrm{~mm}$ from the osteotomy ends, was measured. The distance in all the $15-\mathrm{mm}$ defects as measured after sacrifice $(26.9 \pm 1.4$ $\mathrm{mm})$ was significantly $(p<0.01)$ lower as compared to the postoperative distance $(28.4 \pm 1.2 \mathrm{~mm})$ (Fig. 5). Also for the 20-mm group the defect size after sacrifice $(32.4 \pm 1.2 \mathrm{~mm})$ was significantly $(p<0.001)$ smaller as compared to the postoperative size (33.9 $\pm 0.9 \mathrm{~mm}$ ) (unpaired $t$-test). The epiphyseal plates were closed now, but remnants were still visible indicating that the closure had just occurred.

The results of radiographic scoring with the modified scoring system of defect bridging and bone formation are depicted in Table II. The 15 as well as the $20-\mathrm{mm}$ defect size appeared not to be a critical size, as most defects showed bridging of the bone defect (score $2.4 \pm 1.6$ for $15-\mathrm{mm}$ and score $2.8 \pm 1.4$ for 20-mm defects). No significant differences in defect bridging or degree of bone formation were found between the groups with and without PLGA implants and between the 15-mm group compared to the 20-mm group (chi-square tests).

\section{$\mu \mathrm{CT}$ images}

The results of $\mu \mathrm{CT}$ scoring with the modified scoring system of defect bridging are depicted in Table III. Confirming the radiographic findings, both defect sizes were not of critical size, as score zero [Fig. 6(A)] was only found in a minority of the radii that received no implant. No significant difference in defect bridging was found in the 15- as well as the 20-mm groups between defects with and without PLGA implantation. Also defect bridging did not significantly differ between the 15- and 20-mm groups (chi-square tests).

Comparison of the scoring of the radiographs or three-dimensional $\mu \mathrm{CT}$ images revealed no significant difference in defect bridging between these two evaluation techniques (chi-square tests). However, the $\mu \mathrm{CT}$ images allowed for a more precise evaluation of bone regeneration in the defects. Different kinds of bridging could be distinguished, including a normal or atypical radius contour [Fig. 6(B,C)], which could not be identified in the two-dimensional radiographic pictures. No significant differences in prevalence of these contours between the defects with or without an implant or between the 15- and 20-mm group were found (chi-square tests). The
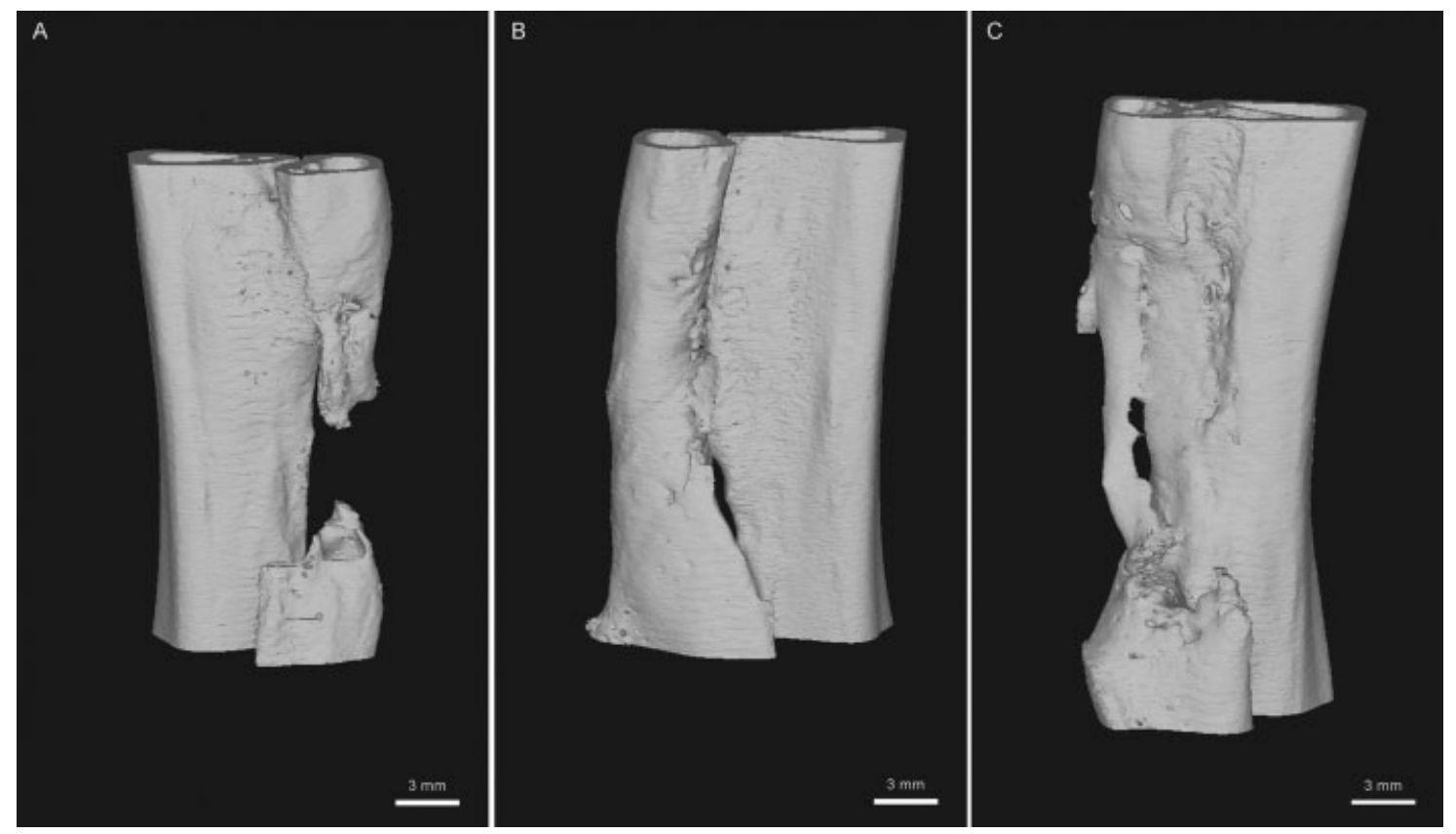

Figure 6. $\mu \mathrm{CT}$ images of radial defects after 12 weeks of implantation: (A) nonbridging, (B) normal radius contour bridging, and (C) atypical radius contour bridging. 


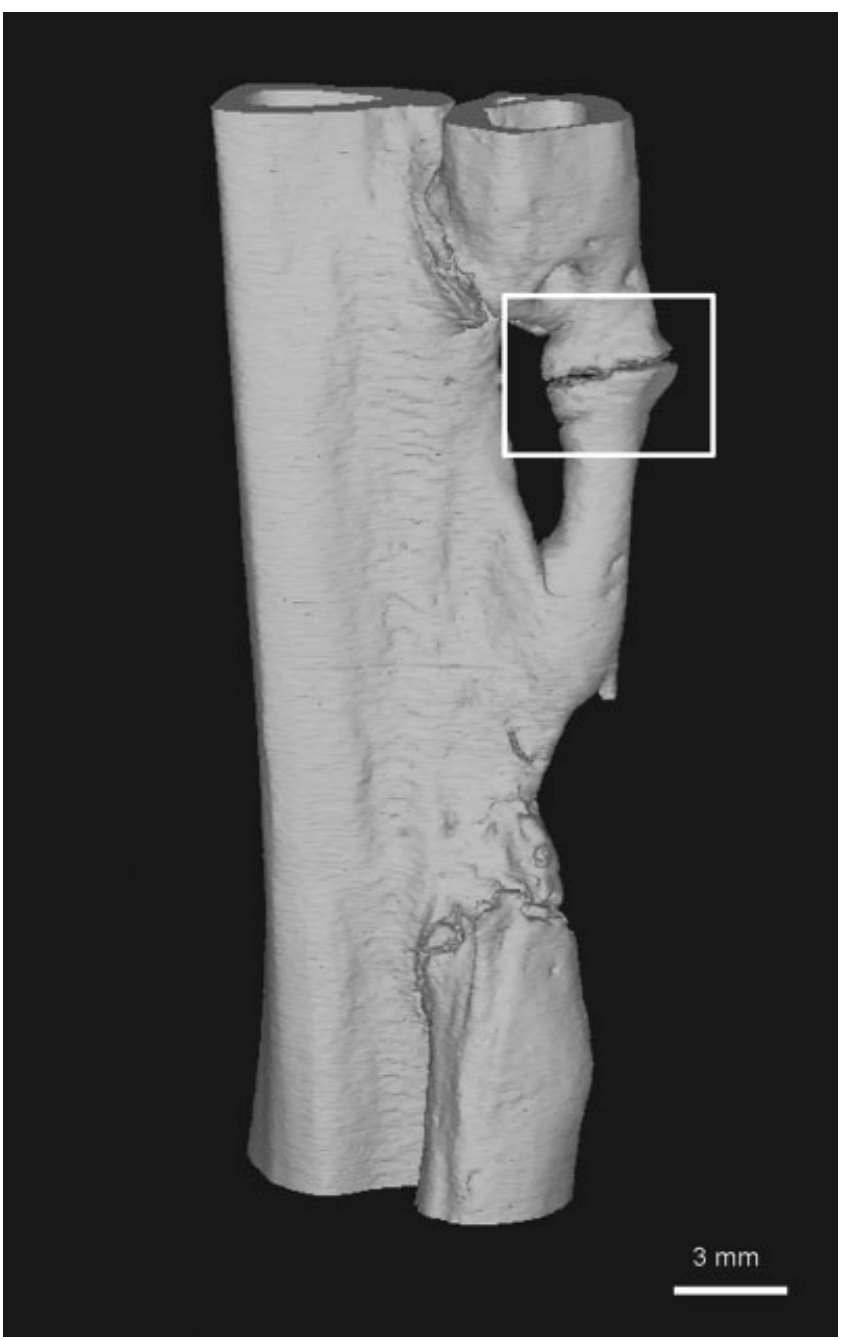

Figure 7. $\mu \mathrm{CT}$ image of a $20-\mathrm{mm}$ defect with an implant after 12 weeks of implantation, showing nonunion.

$\mu \mathrm{CT}$ images also revealed nonunion of the regenerated radius in three specimens of the $20-\mathrm{mm}$ group, characterized by nonalignment of the newly formed bone (Fig. 7).

The results of bone volume $\left(\mathrm{mm}^{3}\right)$ in the ulnar and radial region as determined by $\mu \mathrm{CT}$ are depicted in Table IV. As a reference for ulnar bone, the amount of ulnar bone was measured in the forelimbs of 6-month-old reference rabbits with a radial defect. In the $15-\mathrm{mm}$ defects, the bone volume had signifi- cantly increased after 12 weeks implantation in the defects with and without a PLGA implant as compared to the reference defects $(p<0.0001$, unpaired $t$-test with Welch correction). This indicates that the amount of newly formed bone in the defect was significantly increased compared to the direct postoperative situation. There was no significant difference between the 15-mm group with or without an implant (unpaired $t$-test). Also in the $20-\mathrm{mm}$ defects, bone volume had increased significantly after 12 weeks of implantation as compared to the reference 20 -mm defects $(p<0.0001$, unpaired $t$-test with Welch correction) and no significant difference existed between the 20-mm defect group with and without a PLGA implant (unpaired $t$-test).

\section{Histology}

Gross analysis of the histological sections with light microscopy revealed that in general the tissue reaction was uniform in all specimens, independent of the defect size or the implantation of PLGA. The osteotomy ends could easily be identified. In the specimens that received PLGA microparticles no remains of the implant were found after 12 weeks of implantation. Further, no inflammatory reaction was seen at this time point, as no inflammatory cells or intervening fibrous tissue were noticed.

The longitudinal sections revealed that most specimens showed regeneration of the radius. Bone had formed out of the osteotomy ends or was located at the ulnar surface. Fusion of ulnar and radial bone was seen in almost all samples. The degree of bone remodeling varied between the specimens. Some showed compact newly formed bone, while in other regenerated defects bone marrow formation was apparent (Fig. 8). No difference in the occurrence of this remodeling was found between the groups. In three 20-mm defects, nonunion was observed between the radial osteotomy end and regenerated bone [Fig. 9(A,B)], as characterized by fibrocartilaginous interposed tissue. Histology also revealed cartilage tissue located in the area between the ulna and radius [Fig. 9(C)]. This type of nonunion was found

TABLE IV

The Volume of Bone in the Ulnar and Radial Region $\left(\mathrm{mm}^{3}\right)$ as Determined With $\mu \mathrm{CT}$

\begin{tabular}{lccrr}
\hline & \multicolumn{2}{c}{$15 \mathrm{~mm}$} & \multicolumn{2}{c}{$20 \mathrm{~mm}$} \\
\cline { 2 - 3 } & Reference & Subject & Reference & Subject \\
\hline No implant & $141.7 \pm 9.7$ & $252.3 \pm 38.1^{*}$ & $180.3 \pm 22.3$ & $336.6 \pm 39.5^{*}$ \\
PLGA implant & & $263.5 \pm 40.3^{*}$ & $328.2 \pm 27.9^{*}$ \\
\hline
\end{tabular}

Data represent the mean and standard deviations. Bone formation was significantly ${ }^{*}$ ) increased compared to the reference groups. No significant differences were found between the groups with and without a PLGA implant. 


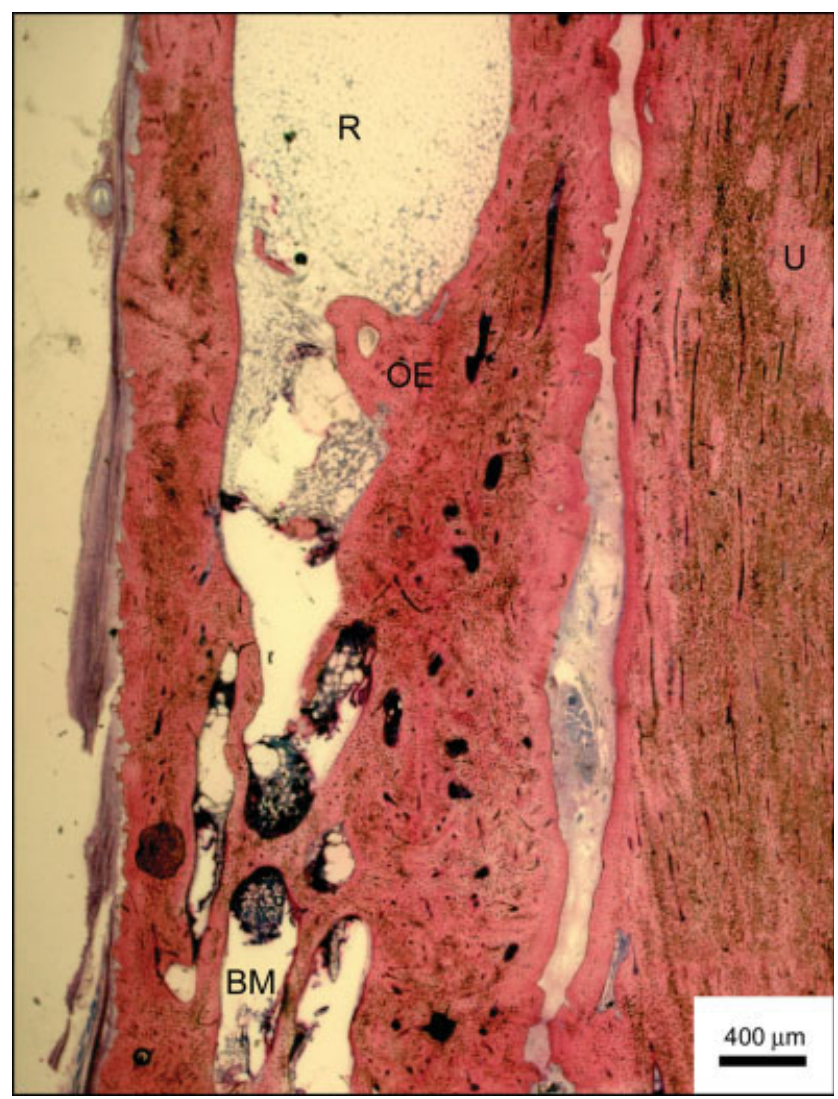

Figure 8. Histological longitudinal section of a $15-\mathrm{mm}$ radius defect with a PLGA implant. The radial bone (R) has regenerated and bone marrow (BM) has formed. OE, radial osteotomy end; $U$, ulnar bone. Methylene blue and basic fuchsin staining. [Color figure can be viewed in the online issue, which is available at www.interscience.wiley. com.] in six of sixteen $20-\mathrm{mm}$ defects and seven of fifteen 15-mm defects.

Bone regeneration not only occurred at the radial osteotomy ends. The transverse sections frequently showed that the ulnar bone had undergone considerable remodeling and hypertrophy (Fig. 10).

\section{DISCUSSION AND CONCLUSION}

Critical-size defects are important to evaluate the bone regenerative effect of artificial bone graft substitutes. In the present study, segmental mid-diaphyseal radial defects of 15 and $20 \mathrm{~mm}$ were created in the forelimbs of 4-month-old New Zealand White rabbits to determine whether this defect size was critical after 12 weeks of implantation. In addition, an implant consisting of PLGA microparticles in a carrier material of CMC was examined for its influence on bone regeneration. Both defect sizes turned out not to be of critical size. Moreover, defect instability was noticed. PLGA/CMC composites did not have a significant effect on bone formation.

The rabbit radius is often used as model for the evaluation of bone regeneration. Defect sizes in the range of 10 to $20 \mathrm{~mm}$ have been described as being of critical size in a series of studies. ${ }^{4,5,7,10-13}$ In the present study, however, a radius defect of 15 as well as of $20 \mathrm{~mm}$ regenerated after 12 weeks of implantation. There are several variables during the study period that can explain this difference in bone regeneration, including the animals, operation technique, implantation time, and the evaluation of the data.

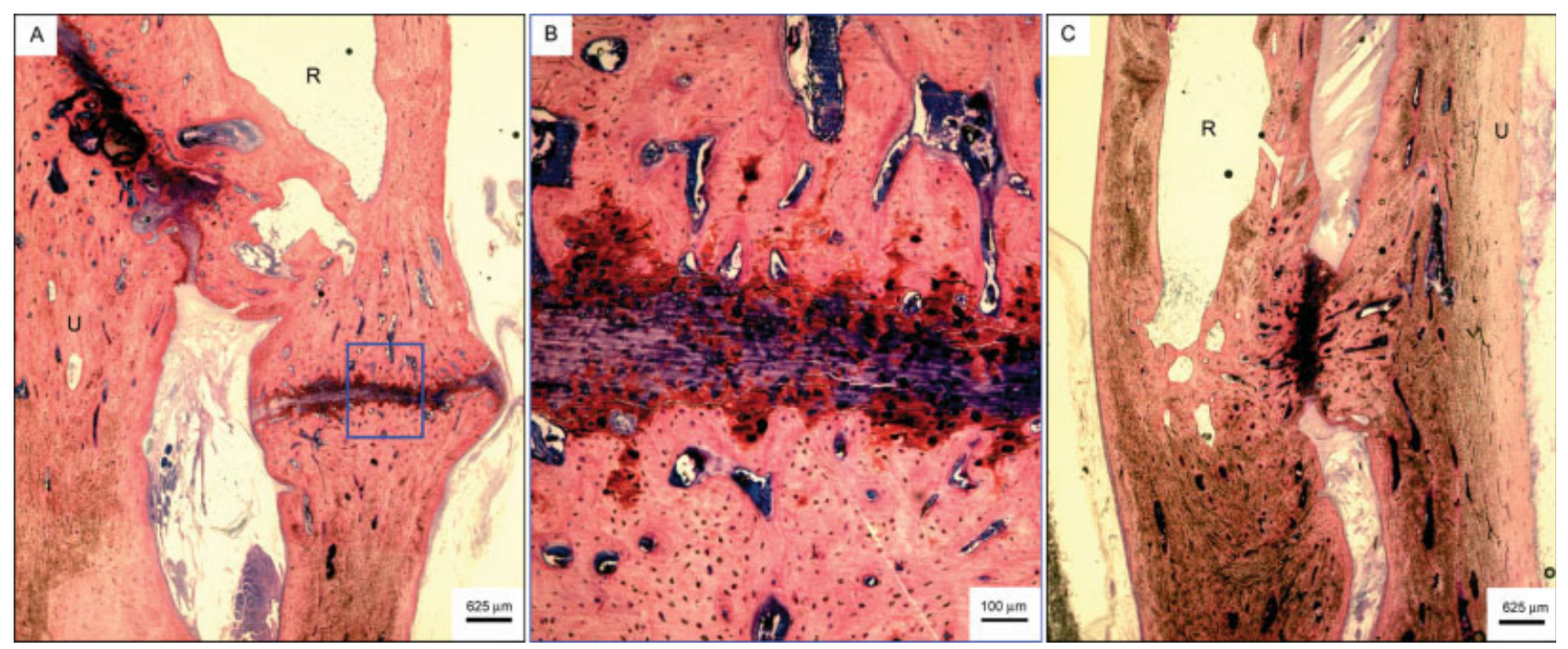

Figure 9. Histological longitudinal sections showing nonunion (A) in the regenerated radius of a 20-mm defect with an implant with the (B) magnification of the fibrocartilaginous interposition. (C) Nonunion located in the area between the ulna and radius of a 15-mm defect without an implant. R, radius; $\mathrm{U}$, ulna. Methylene blue and basic fuchsin staining. [Color figure can be viewed in the online issue, which is available at www.interscience.wiley.com.] 


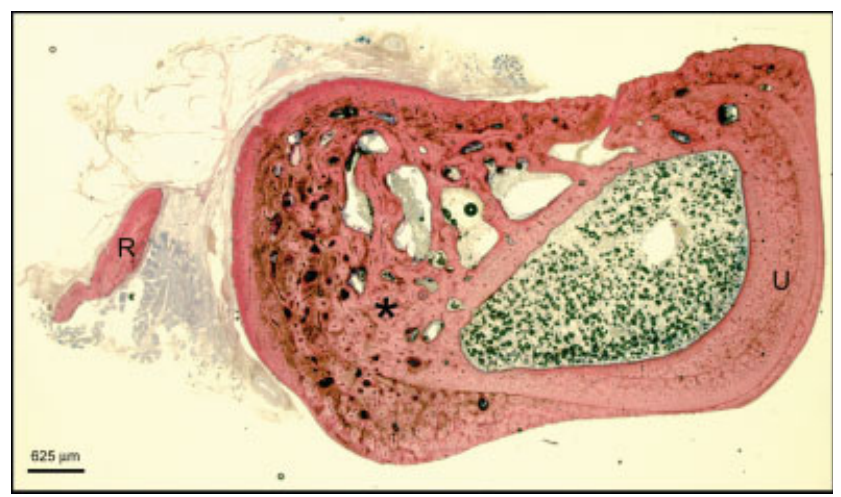

Figure 10. Cross-sectional photomicrograph of a 15-mm radial defect without a PLGA implant. Ulnar hypertrophy can be noticed $\left({ }^{*}\right)$. U, ulna; $R$, regenerated radius. Methylene blue and basic fuchsin staining. [Color figure can be viewed in the online issue, which is available at www. interscience.wiley.com.]

Starting with the experimental animals, age might be an important factor in bone regenerative behavior. In the present study, 4-month-old rabbits were included. Previous studies dealing with critical-sized diaphyseal radial defects did not mention the age of the rabbits ${ }^{4,7,13}$ or only cited that the epiphyseal plates were closed on radiographs. ${ }^{5,10,11}$ It has to be noticed that, besides epiphysis obliteration, the age of the rabbits has to be provided as discrepancy exists in radiographic and histological epiphyseal closure $^{37}$ and in closure of different epiphyses within the same animal or even at the opposite ends of the same bone. ${ }^{38}$ Although by 16 weeks of age long bones have reached about $95 \%$ of their adult length in rabbits, ${ }^{38}$ the skeletal growth of New Zealand White Rabbits is complete between 19 and 32 weeks. ${ }^{37,39}$ Therefore, it can be supposed that the animals as used in our study were not mature enough and still possessed a high potential of regeneration similar to newborn animals. ${ }^{3,40,41}$ In view of this, the use of rabbits older than 6 months should be recommended for bone regenerative studies.

Besides the animal model, the surgical technique used could have affected defect regeneration. Gentle drilling under saline cooling will result in better regeneration compared to more brutal techniques, which might destroy bone tissue. In addition, it is conceivable that the experience and skill of the surgeon are also associated with bridging of the defect. In our study, the periosteum and interosseous membrane were removed, as these could accelerate bone regeneration. ${ }^{42}$ However, an opposite effect of this tissue removal might have occurred. Frequently, ulnar hypertrophy was observed, which might have been caused by scratching of the ulnar bone surface. Simon et al. ${ }^{43}$ studied the effect of incising the tibial bone surface in goats and found that cambium cells were stimulated, resulting in callus matrix synthesis. In addition, $\mathrm{O}^{\prime}$ Driscoll et al. ${ }^{44}$ outlined the complexity of periosteal harvesting in rabbits, as the cambium layer is only lightly adherent to the fibrous layer and can easily be left behind when the periosteum is harvested. Hypothetically, in the present study with the removal of periosteal tissue, cambium cells might have remained and the removal process may have stimulated these cambium cells and induced osteogenesis. In previous studies, ulnar hypertrophy was not mentioned or ulnar bone growth was not defined as defect bridging. ${ }^{5,7}$ Nevertheless, the effect of cambium cell stimulation might be trivial in older rabbits as the cambium cells diminish with age. ${ }^{45}$

The implantation time can play a role as well. Some studies showing nonbridging of rabbit radial defects used implantation times of 4-8 weeks ${ }^{4,10,11,13}$ instead of 12 weeks as used in the present study. It might be that the period between 8 and 12 weeks enclosed the critical transition to closure of the defect. As described in the Introduction, the definition of a CSD encloses a time span. Hypothetically, small bone defects will not heal spontaneously when the lifetime of experimental animals is short enough. To fulfill the definition of a CSD, however, the animal lifetime should enclose at least a complete bone remodeling cycle. ${ }^{3}$ Bone remodeling in humans takes about 2 to 8 months, ${ }^{46}$ in animals this can be shorter. ${ }^{40}$ We therefore recommend a study period of at least 12 weeks for the evaluation of bone formation in CSD models.

Finally, differences occur in the evaluation of the data between various studies, which can result in different conclusions about bridging of created bone defects. As mentioned before, ulnar hypertrophy is not always considered as defect bridging., 5 Also a less stringent scoring system leads to fewer defects rated as nonbridged. ${ }^{10}$ Further, three-dimensional evaluation of bone bridging using additional $\mu \mathrm{CT}$ images is more accurate than two-dimensional evaluation techniques using radiographs and histology alone. ${ }^{16}$ The present study confirmed this, as each evaluation technique has its own contribution to the evaluation of the data. $\mu \mathrm{CT}$ images revealed several types of defect bridging which could not be detected with radiographs alone. Further, the histological sections exposed nonunion, which was not always visible in the $\mu \mathrm{CT}$ images.

One of the reasons why the rabbit radius is a favorite model for evaluating bone regeneration is that the intact adjacent ulna is supposed to provide stability to the created radial defect without the need for internal or external fixation of the forelimb. ${ }^{4-8}$ In our study it was possible to measure the actual defect size after surgery and sacrifice, as we marked the osteotomy ends with titanium. According to our 
knowledge, comparison of the postoperative and post-sacrifice defect sizes has not been done before. We noticed that the distance between the titanium markers became significantly shorter after 12 weeks of implantation in the $15-$ as well as the $20-\mathrm{mm}$ group. In addition, nonunion was found in several regenerated defects of both groups. These findings indicate that the ulna was not able to immobilize the created radial defect optimally. ${ }^{47}$ Evidently, the rabbit radius is not a suitable model for bone regeneration, without additional fixation of the osteotomy ends, beyond the discussion whether the defect sizes are critical or not.

Another known critical-size long bone model is the rabbit femur. ${ }^{48}$ In this model, however, the use of osteosynthesis material such as screw plates and intramedullar Kirschner wires is unavoidable. Consequently, infection risk and interference in bone regeneration cannot be excluded. The search for new self-stabilizing bone defects in rabbits is of interest for future synthetic bone graft investigations as implantation in a validated small animal model is a prerequisite before large animal implantation. ${ }^{49}$ So far, only the $15-\mathrm{mm}$ calvarial defect seems to be a reliable CSD model complying with these requisites in rabbits. $3,50,51$ In goats the os ilium has shown potential for producing critical-sized defects. ${ }^{51}$ This ilium model might also be engaged in rabbits.

PLGA microparticles were examined in this study for their influence on bone regeneration. After 12 weeks of implantation no remnants of the PLGA implant were found in the histological sections. PLGA degrades by hydrolytic cleavage of its polymer chains. ${ }^{22}$ The protons released during degradation can cause acidity, which can result in inflammation and tissue necrosis when the clearance of the degradation products is not adequate ${ }^{24}$ or due to a delay in further metabolism to carbon oxide and water. ${ }^{25}$ In the present study, no differences in bone formation or inflammation were found between control and implant groups after 12 weeks of implantation. The effect of acidity is apparently negligible for small amounts of PLGA in microparticle form, although it has to be mentioned that the biochemical and mechanical aspects of the newly formed bone were not examined in the present study. The finding of negligible acidity agrees with clinical studies in patients, where porous or sponge-like PLGA root replicas were well tolerated in post-extraction alveolar socket healing. ${ }^{52,53}$ In contrast, dense PLGA implants caused an initial temporary lactic acid induced decalcification of the alveolar process. $^{52}$ Nevertheless, it has to be noted that the mechanism of PLGA-microparticle clearance is not known in the current study, as no short-term follow-up was performed. The mechanisms involved could include degradation, dissolution or even migration, with the latter resulting in a possible false neutral influence on bone regeneration.

In conclusion, CSD models are important for the evaluation of synthetic bone grafts, but the radius of four month old New Zealand White Rabbits is not a suitable location for this model, because 15- and 20-mm defects were not of critical size and no stable defect could be created. PLGA-microparticle degradation did not influence bone formation.

The CMC used in this study was kindly provided by Noviant BV, Nijmegen, the Netherlands. The authors would like to thank Dr. Ir. E. Bronkhorst for his assistance with statistical analysis and S. Young for critically reading the manuscript.

\section{References}

1. DeCoster TA, Gehlert RJ, Mikola EA, Pirela-Cruz MA. Management of posttraumatic segmental bone defects. J Am Acad Orthop Surg 2004;12:28-38.

2. Bos GD, Goldberg VM, Powell AE, Heiple KG, Zika JM. The effect of histocompatibility matching on canine frozen bone allografts. J Bone Joint Surg Am 1983;65:89-96.

3. Schmitz JP, Hollinger JO. The critical size defect as an experimental model for craniomandibulofacial nonunions. Clin Orthop Relat Res 1986;205:299-308.

4. Wheeler DL, Chamberland DL, Schmitt JM, Buck DC, Brekke JH, Hollinger JO, Joh SP, Suh KW. Radiomorphometry and biomechanical assessment of recombinant human bone morphogenetic protein 2 and polymer in rabbit radius ostectomy model. J Biomed Mater Res 1998;43:365-373.

5. Meinig RP, Rahn B, Perren SM, Gogolewski S. Bone regeneration with resorbable polymeric membranes: Treatment of diaphyseal bone defects in the rabbit radius with poly(L-lactide) membrane. A pilot study. J Orthop Trauma 1996;10:178-190.

6. Hedberg EL, Kroese-Deutman HC, Shih CK, Crowther RS, Carney DH, Mikos AG, Jansen JA. Effect of varied release kinetics of the osteogenic thrombin peptide TP508 from biodegradable, polymeric scaffolds on bone formation in vivo. J Biomed Mater Res A 2005;72A:343-353.

7. Meinig RP. Polylactide membranes in the treatment of segmental diaphyseal defects: Animal model experiments in the rabbit radius, sheep tibia, Yucatan minipig radius, and goat tibia. Injury 2002;33:B58-B65.

8. Geiger F, Bertram H, Berger I, Lorenz H, Wall O, Eckhardt C, Simank HG, Richter W. Vascular endothelial growth factor gene-activated matrix (VEGF165-GAM) enhances osteogenesis and angiogenesis in large segmental bone defects. J Bone Miner Res 2005;20:2028-2035.

9. Solheim E, Pinholt EM, Andersen R, Bang G, Sudmann E. The effect of a composite of polyorthoester and demineralized bone on the healing of large segmental defects of the radius in rats. J Bone Joint Surg Am 1992;74:1456-1463.

10. Beck LS, Wong RL, DeGuzman L, Lee WP, Ongpipattanakul B, Nguyen TH. Combination of bone marrow and TGF-beta1 augment the healing of critical-sized bone defects. J Pharm Sci 1998;87:1379-1386.

11. Zegzula HD, Buck DC, Brekke J, Wozney JM, Hollinger JO. Bone formation with use of rhBMP-2 (recombinant human bone morphogenetic protein-2). J Bone Joint Surg Am 1997; 79:1778-1790.

12. Nyman R, Magnusson M, Sennerby L, Nyman S, Lundgren D. Membrane-guided bone regeneration. Segmental radius 
defects studied in the rabbit. Acta Orthop Scand 1995; 66:169-173.

13. Kaito T, Myoui A, Takaoka K, Saito N, Nishikawa M, Tamai $\mathrm{N}$, Ohgushi H, Yoshikawa H. Potentiation of the activity of bone morphogenetic protein-2 in bone regeneration by a PLA-PEG/hydroxyapatite composite. Biomaterials 2005;26: 73-79.

14. Hedberg EL, Kroese-Deutman HC, Shih CK, Crowther RS, Carney DH, Mikos AG, Jansen JA. In vivo degradation of porous poly(propylene fumarate)/poly(DL-lactic-co-glycolic acid) composite scaffolds. Biomaterials 2005;26:4616-4623.

15. Weiss P, Obadia L, Magne D, Bourges X, Rau C, Weitkamp T, Khairoun I, Bouler JM, Chappard D, Gauthier O, Daculsi G. Synchrotron X-ray microtomography (on a micron scale) provides three-dimensional imaging representation of bone ingrowth in calcium phosphate biomaterials. Biomaterials 2003;24:4591-4601.

16. Hedberg EL, Kroese-Deutman HC, Shih CK, Lemoine JJ, Liebschner MAK, Miller MJ, Yasko AW, Crowther RS, Carney DH, Mikos AG, Jansen JA. Methods: A comparative analysis of radiography, microcomputed tomography, and histology for bone tissue engineering. Tissue Eng 2005;11:1356-1367.

17. Schmidhammer R, Zandieh S, Mittermayr R, Linda E, Pelinka LE, Leixnering M, Hopf R, Kroepfl A, Redl H. Assessment of bone union/nonunion in an experimental model using microcomputed technology. J Trauma 2006;61:199-205.

18. del Real RP, Ooms E, Wolke JG, Vallet-Regi M, Jansen JA. In vivo bone response to porous calcium phosphate cement. J Biomed Mater Res A 2003;65A:30-36.

19. Ruhe PQ, Hedberg EL, Padron NT, Spauwen PH, Jansen JA, Mikos AG. rhBMP-2 release from injectable poly(DL-lactic-coglycolic acid)/calcium-phosphate cement composites. J Bone Joint Surg Am 2003;85A:75-81.

20. Ruhe PQ, Boerman OC, Russel FG, Spauwen PH, Mikos AG, Jansen JA. Controlled release of rhBMP-2 loaded poly(DL-lactic-co-glycolic acid)/calcium phosphate cement composites in vivo. J Control Release 2005;106:162-171.

21. Agrawal CM, Ray RB. Biodegradable polymeric scaffolds for musculoskeletal tissue engineering. J Biomed Mater Res 2001; 55:141-150.

22. Shive MS, Anderson JM. Biodegradation and biocompatibility of PLA and PLGA microspheres. Adv Drug Deliv Rev 1997;28:5-24.

23. Ignatius AA, Claes LE. In vitro biocompatibility of bioresorbable polymers: Poly(L, DL-lactide) and poly(L-lactide-co-glycolide). Biomaterials 1996;17:831-839.

24. Simon CG Jr, Khatri CA, Wight SA, Wang FW. Preliminary report on the biocompatibility of a moldable, resorbable, composite bone graft consisting of calcium phosphate cement and poly(lactide-co-glycolide) microspheres. J Orthop Res 2002;20:473-482.

25. Peltoniemi H, Ashammakhi N, Kontio R, Waris $\mathrm{T}$, Salo A, Lindqvist C, Gratz K, Suuronen R. The use of bioabsorbable osteofixation devices in craniomaxillofacial surgery. Oral Surg Oral Med Oral Pathol Oral Radiol Endod 2002;94:5-14.

26. Habraken W.J.E.M, Wolke JGC, Mikos AG, Jansen JA. Injectable PLGA microsphere/calcium phosphate cements: Physical properties and degradation characteristics 2006;17:10571074.

27. Sannino A, Esposito A, De Rosa A, Cozzolino A, Ambrosio L, Nicolais L. Biomedical application of a superabsorbent hydrogel for body water elimination in the treatment of edemas. J Biomed Mater Res A 2003;67A:1016-1024.

28. Santa-Comba A, Pereira A, Lemos R, Santos D, Amarante J, Pinto M, Tavares P, Bahia F. Evaluation of carboxymethylcellulose, hydroxypropylmethylcellulose, and aluminum hydroxide as potential carriers for rhBMP-2. J Biomed Mater Res 2001;55:396-400.
29. Pluhar GE, Turner AS, Pierce AR, Toth CA, Wheeler DL. A comparison of two biomaterial carriers for osteogenic protein-1 (BMP-7) in an ovine critical defect model. J Bone Joint Surg Br 2006;88:960-966.

30. Wang H, Springer IN, Schildberg H, Acil Y, Ludwig K, Rueger DR, Terheyden H. Carboxymethylcellulose-stabilized collagenous rhOP-1 device-A novel carrier biomaterial for the repair of mandibular continuity defects. J Biomed Mater Res A 2004;68A:219-226.

31. Song HR, Oh CW, Kyung HS, Park IH, kim PT, Baek SH, Kim SJ, Lee ST. Injected calcium sulfate for consolidation of distraction osteogenesis in rabbit tibia. J Pediatr Orthop B 2004;13:170-175.

32. Lu L, Stamatas GN, Mikos AG. Controlled release of transforming growth factor beta1 from biodegradable polymer microparticles. J Biomed Mater Res 2000;50:440-451.

33. Peter SJ, Lu L, Kim DJ, Stamatas GN, Miller MJ, Yaszemski MJ, Mikos AG. Effects of transforming growth factor beta1 released from biodegradable polymer microparticles on marrow stromal osteoblasts cultured on poly(propylene fumarate) substrates. J Biomed Mater Res 2000;50:452-462.

34. Cleek RL, Rege AA, Denner LA, Eskin SG, Mikos AG. Inhibition of smooth muscle cell growth in vitro by an antisense oligodeoxynucleotide released from poly(DL-lactic-co-glycolic acid) microparticles. J Biomed Mater Res 1997;35:525-530.

35. Aspenberg P. Drugs and fracture repair. Acta Orthop 2005;76:741-748.

36. Bourne MH. Analgesics for orthopedic postoperative pain. Am J Orthop 2004;33:128-135.

37. Kaweblum M, Aguilar MC, Blancas E, Kaweblum J, Lehman WB, Grant AD, Strongwater AM. Histological and radiographic determination of the age of physeal closure of the distal femur, proximal tibia, and proximal fibula of the New Zealand white rabbit. J Orthop Res 1994;12:747-749.

38. Rivas R, Shapiro F. Structural stages in the development of the long bones and epiphyses: A study in the New Zealand white rabbit. J Bone Joint Surg Am 2002;84A:85-100.

39. Masoud I, Shapiro F, Kent R, Moses A. A longitudinal study of the growth of the New Zealand white rabbit: Cumulative and biweekly incremental growth rates for body length, body weight, femoral length, and tibial length. J Orthop Res 1986;4:221-231.

40. Bosch C, Melsen B, Vargervik K. Importance of the criticalsize bone defect in testing bone-regenerating materials. J Craniofac Surg 1998;9:310-316.

41. Takagi K, Urist MR. The reaction of the dura to bone morphogenetic protein (bmp) in repair of skull defects. Ann Surg. 1982;196:100-109.

42. Fujii T, Ueno T, Kagawa T, Sakata Y, Sugahara T. Comparison of bone formation ingrafted periosteum harvested from tibia and calvaria. Microsc Res Technol 2006;69:580-584.

43. Simon TM, Van Sickle DC, Kunishima DH, Jackson DW. Cambium cell stimulation from surgical release of the periosteum. J Orthop Res 2003;21:470-480.

44. O'Driscoll SW. Articular cartilage regeneration using periosteum. Clin Orthop Relat Res 1999;367:S186-S203.

45. O'Driscoll SW, Saris DB, Ito Y, Fitzimmons JS. The chondrogenic potential of periosteum decreases with age. J Orthop Res 2001;19:95-103.

46. Fernandez-Tresguerres-Hernandez-Gil I, Alobera-Gracia MA, del-Canto-Pingarron M, Blanco-Jerez L. Physiological bases of bone regeneration II. The remodeling process. Med Oral Patol Oral Cir Bucal 2006;11:E151-E157.

47. Rodriguez-Merchan EC, Forriol F. Nonunion: General principles and experimental data. Clin Orthop Relat Res 2004;419:4-12.

48. Gil-Albarova J, Salinas AJ, Bueno-Lozano AL, Roman J, Aldini-Nicolo N, Garcia-Barea A, Giavaresi G, Fini M, Giar- 
dino R, Vallet-Regi M. The in vivo behaviour of a sol-gel glass and a glass-ceramic during critical diaphyseal bone defects healing. Biomaterials 2005;26:4374-4382.

49. Le Guehennec L, Goyenvalle E, Aguado E, HouchmandCuny M, Enkel B, Pilet P, Daculsi G, Layrolle P. Small-animal models for testing macroporous ceramic bone substitutes. J Biomed Mater Res B Appl Biomater 2005;72:69-78.

50. Hollinger JO, Kleinschmidt JC. The critical size defect as an experimental model to test bone repair materials. J Craniofac Surg 1990;1:60-68.

51. Anderson ML, Dhert WJ, de Bruijn JD, Dalmeijer RAJ, Leenders $\mathrm{H}$, van Blitterswijk CA, Verbout AJ. Critical size defect in the goat's os ilium. A model to evaluate bone grafts and substitutes. Clin Orthop Relat Res 1999;364:231-239.

52. Nair Pn PR, Schug J. Observations on healing of human tooth extraction sockets implanted with bioabsorbable polylacticpolyglycolic acids (PLGA) copolymer root replicas: A clinical, radiographic, and histologic follow-up report of 8 cases. Oral Surg Oral Med Oral Pathol Oral Radiol Endod 2004; 97:559-569.

53. Serino G, Biancu S, Iezzi G, Piattelli A. Ridge preservation following tooth extraction using a polylactide and polyglycolide sponge as space filler: A clinical and histological study in humans. Clin Oral Implants Res 2003;14:651-658. 